CUADERNOS DE ESTUDIOS GALLEGOS, LXII Núm. 128 (enero-diciembre 2015), págs. 249-279

ISSN: $0210-847 \mathrm{X}$

DOI: $10.3989 /$ ceg.2015.128.08

\title{
LOS GALLEGOS EN EL PERÚ: LA MIGRACIÓN DE LOS MALPICÁNS AL PUERTO DE CHIMBOTE
}

\author{
José A. Valverde Elera*
}

Universidade da Coruña

* Doctorando en Investigación en Migraciones Internacionales. 


\section{LOS GALLEGOS EN EL PERÚ: LA MIGRACIÓN DE LOS MALPICÁNS AL PUERTO DE CHIMBOTE}

RESUMEN

El objetivo de este artículo es presentar un breve trabajo histórico con aportes bibliográficos y etnográficos, respecto a la migración de la población del Concello de Malpica de Bergantiños hacia el puerto peruano de Chimbote, en la segunda mitad del siglo anterior, durante los años de bonanza pesquera en este país.

Este trabajo es parte de una tesis doctoral en vías de realización denominada Perú y Galicia: la migración antes y ahora. La recopilación de la información se inició a mediados de 2012 en el puerto de Malpica de Bergantiños y continúa a la fecha en Perú. Para este artículo, nos hemos basado en investigaciones previas y en los datos obtenidos de nuestras entrevistas con los mismos actores, quienes han narrado sus experiencias migratorias.

Creemos que rescatar la memoria de este proceso migratorio, pone de relevancia una realidad actual y pasada: el desplazamiento de las personas fuera de sus países para buscar mejorar sus condiciones de vida. Pues actualmente en este puerto gallego confluyen dos generaciones de inmigrados, los peruanos que actualmente viven allí y trabajan en la pesca y los malpicáns que años atrás migraron al Perú, donde se les brindó acogida y trabajo.

Palabras Clave: Migración, Malpica de Bergantiños, Chimbote, pesca, redes migratorias.

\section{OS GALEGOS NO PERÚ: A MIGRACIÓN DOS MALPICÁNS AO PORTO DE CHIMBOTE RESUMO}

O obxectivo deste artigo é presentar un breve traballo histórico con achegas bibliográficas e etnográficas, respecto á migración da poboación do Concello de Malpica de Bergantiños cara ao porto peruano de Chimbote, na segunda metade do século anterior, durante os anos de bonanza pesqueira neste país. Este traballo é parte dunha tese doutoral en vías de realización denominada Perú e Galicia: a migración antes e agora. A recompilación da información iniciouse a mediados de 2012 no porto de Malpica de Bergantiños e continúa á data en Perú. Para este artigo, baseámonos en investigacións previas e nos datos obtidos das nosas entrevistas cos mesmos actores, os cales narraron as súas experiencias migratorias. Cremos que rescatar a memoria deste proceso migratorio, pon de relevancia unha realidade actual e pasada: o desprazamento das persoas fose dos seus países para buscar mellorar as súas condicións de vida. Pois actualmente neste porto galego conflúen dúas xeracións de inmigrados, os peruanos que actualmente viven alí e traballan na pesca e os malpicáns que anos atrás migraron ao Perú, onde se lles brindou acollida e traballo.

Palabras ClaVe: Migración, Malpica de Bergantiños, Chimbote, pesca, redes migratorias.

\section{GALICIANS IN PERU: THE MIGRATION OF THE MALPICANS TO THE PORT OF CHIMBOTE}

Abstract

The aim of this paper is to present a brief historical study with bibliographical and ethnographical contributions on the migration of people from the Concello de Malpica de Bergantiños to the peruvian port of Chimbote, during the second half of the past century, when Peru was experiencing a fishing bonanza. This paper is part of a doctoral thesis in progress called Peru and Galicia:migration before and now. Fieldwork began in mid-2012 in the port of Malpica de Bergantiños and continues today in Perú. Previous research done by others has been the basis of our investigation to which we have added data obtained from our personal interviews with the actors themselves, who gave us an account their migration experiences.

We believe that recovering this migration process highlights an old and on the same time new reality: this movement of people outside their countries to look for better life conditions. Nowadays, two generations of immigrants converge in this Galician harbour, the Peruvian sailors who live there and the "malpicans", who migrated to Perú years back, where they were given shelter and work. KEY WORDs: Migration, Malpica of Bergantiños, Chimbote, fishing, migratory networks. 
Recibido/Received: 19/05/2015

Aceptado/Accepted: 10/08/2015

1. BREVE REFERENCIA SOBRE LOS ESTUdios DE LA EMIGRACIÓN GALLEGA HACIA el Perú

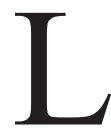

a emigración gallega ha sido motivo de diversos e importantes estudios desde hace muchos años, cobrando mayor protagonismo con la creación en 1992 del Archivo de la Emigración Gallega (AEG), lo que ha permitido tener una cronología más o menos exacta de la misma. Así, podemos señalar que desde el siglo XVIII han existido migraciones estacionales de grupos de jornaleros agrícolas gallegos que se desplazaban a Portugal, Castilla y Andalucía. A partir de 1830 se sumaron diversos flujos migratorios transoceánicos que tuvieron como destinos principales Cuba, Argentina, Uruguay, Brasil y Estados Unidos. Desde 1960 los flujos migratorios hacia América comenzaron su decadencia, frente al surgimiento de modernos flujos intraeuropeos dirigidos a los núcleos industriales de España, Alemania, Suiza y Francia. Sin embargo a la par de este flujo migratorio al interior de Europa y desde años anteriores, existieron otros destinos migratorios para los gallegos en América, como Venezuela, Chile y Perú, destacando el primero, que empezará a cobrar presencia después de la Guerra Civil española ${ }^{1}$.

Respecto al tema que nos interesa, la migración gallega hacia el Perú no consigna mayores datos estadísticos, pues estudios realizados entre los españoles afincados en el Perú entre 1870 y 1945, dan cuenta de la inexistencia en este país de un registro central de extranjería ${ }^{2}$. Sin embargo, algunos autores ofrecen algunos datos y cifras al respecto, usando información tomada en los puertos de partida. En ese sentido, podemos señalar que entre 1860 y 1870 algunos centenares de gallegos (coruñeses) emigraron hacia Perú. A finales de aquel siglo, no fueron

\footnotetext{
1 Alexandre VÁzQuez GonzÁlez, “A emigración galega contemporánea”, en Xosé Cid Fernández, Xoán Dominguez Alberte y Raúl Sotelo Vásquez (coords.), Migracións na Galicia contemporánea. Desafios para a sociedade actual, Santiago de Compostela, Sotelo blanco edicións, 2008, págs. 18-36. y Antonio Eiras Roel y Ofelia Rey Castelao, Los gallegos y América, Madrid, Editorial MAPFRE, 1992, pág. 261.

2 Nuria Sala I VILA, "Cobertura y desamparo: garantías jurídicas de los españoles en el Perú (18701945)”, Anuario de Estudios Americanos, 66,1 (enero-junio.2009), pág. 132.
} 
más de cien los gallegos que se dirigieron a este país, aunque esta vez casi todos eran pontevedreses. En 1871-1875 un empresario llevó a este país 171 emigrantes gallegos, otorgándoles pasajes, tierra y semillas, contra entrega de la mitad de la cosecha durante un cierto número de años; iniciativa que no tuvo éxito, pues no logró continuidad. Entre 1885 y 1895, según cifras oficiales, llegaron a Perú 59 gallegos; 19 provenían de Coruña, 3 de Lugo, 2 de Ourense y 35 de Pontevedra. También existen dos registros de llegadas de gallegos al Perú; uno de 1913 nos indica que 36 llegaron a este país, embarcándose en el puerto de Vigo; y que en 1914, fueron 7 los gallegos que lo hicieron, viajando desde el puerto de La Coruña ${ }^{3}$. Entre 1961 y 1990, se registró que ingresaron al Perú procedentes de La Coruña, 14 varones y 25 mujeres, siendo el período comprendido entre 1962 y 1966 el de mayor flujo de migrantes gallegos hacia este país ${ }^{4}$.

El Perú, por motivos que pueden ser materia de futuras investigaciones, no fue un destino importante para la emigración gallega, y hasta hace pocos años, se hacían breves referencias sobre esta en algunos textos. Sin embargo, y gracias a los intentos de recuperación de la memoria histórica en Galicia, se han realizados algunas investigaciones sobre esta migración en dos contextos históricos: durante la explotación del caucho en la Amazonía (1870-1920) y durante el auge de la industria pesquera en el Perú (1950-1970). La primera, basada principalmente en biografías y trayectorias migratorias personales o familiares; y la segunda, abordando el tema de los flujos migratorios por motivos laborales y reagrupaciones familiares.

Respecto a la presencia gallega durante la explotación cauchera en la selva del Perú, Maximino Fernández Sendín, publicó en 2005, Alfonso I de la Amazonía Rey de los Jibaros, donde narra la biografía del ourensano Alfonso Graña, cuya vida en la Amazonía peruana linda entre el mito y la realidad, y de quién se dice llegó a ser jefe de numerosas tribus y tener bajo su dominio amplios territorios de la selva limítrofes con Ecuador, a tal punto de que la empresa norteamericana Standard Oil tuvo que llegar a un acuerdo con él para poder trabajar en la zona ${ }^{5}$. Ascención Martínez Riaza, publicó en 2006 su trabajo A pesar del Gobierno: Españoles en el Perú, 1879-1939, donde estudia la forma como algunos peninsulares lograron hacer fortuna y se integraron a las élites y a los espacios de poder en el Perú en el marco de la política oficial entre este país y España, destacando

\footnotetext{
3 Antonio Eiras Roel y Ofelia Rey Castelao, Los gallegos y América ..., págs. 215-266.

4 María Teresa García Domínguez, "A emigración galega cara a América durante a segunda mitade do século XX", en Pilar Cagiao Vila (compiladora), Galegos en América e Americanos en Galicia: as colectividades inmigrantes en América e a súa impronta na sociedade galega, séculos XIX-XX, Santiago de Compostela, Xunta de Galicia, 1999, págs. 73-75.

5 Maximino Fernández Sendín, Alfonso I de la Amazonía Rey de los Jíbaros, Pontevedra, Autoreditor, 2005.
} 
entre ellos algunos gallegos que trabajaron en las regiones selváticas de Loreto y Madre de Dios 6 .

Entre los gallegos dedicados a la explotación del caucho, destacaron los hermanos Barcia (Pontevedra), quienes formaron una de las casas comerciales del caucho más grandes en Perú. La historia de ellos es relatada en un texto de Marta Candeira Carballido, Los hermanos Barcia: caucheros y filántropos, publicado en $2010^{7}$. Por otra parte, Nuria Silva i Vila en un texto publicado en 2009 Cobertura y Desamparo: garantías jurídicas de los españoles en el Perú (1870-1945), hace mención de varios caucheros y comerciantes gallegos instalados a lo largo del país andino y principalmente en la Amazonía, abordando los casos de algunos españoles afincados en el Perú que valiéndose de su nacionalidad, acudían a sus Consulados en busca de ayuda y usaban diferentes mecanismos para defender sus intereses económicos ante diversos acontecimientos políticos y sociales de esa época ${ }^{8}$.

Respecto a la migración gallega más reciente y principalmente durante el auge de la industria pesquera en el Perú, destacan los trabajos de María Teresa García Domínguez y de Ana Chouciño Fernández. La primera ha realizado tres publicaciones al respecto: en 1992 A Emigración Galega a América no Século XX: O caso peruano ${ }^{9}$; en 1998 Aproximación ó estudio da emigración galega da “Costa da Morte" cara a Perú na segunda metade do século XX (1940-1970)10. y en 2013 Outros países de acollida: Chile, Perú11. En estos tres trabajos realiza una semblanza histórica de la migración gallega hacia el Perú, haciendo uso de diversas fuentes escritas y orales, mostrando el funcionamiento de las cadenas y redes migratorias ${ }^{12}$, y resaltando la figura de Benigno Lago como un empresario

\footnotetext{
${ }^{6}$ Ascensión Martínez Riaza, A pesar del Gobierno: Españoles en el Perú, 1879-1939, Madrid, Consejo Superior de Investigaciones Científicas, 2006 (Colección América, 4), págs. 261-280.

7 Marta Candeira Carballido, Los hermanos Barcia: caucheros y filántropos, Vigo, Editorial Galicia en el Mundo (Colección Crónicas de la Emigración), 2010.

8 N. SALA I VILA, "Cobertura y desamparo...", págs. 103- 133.

9 María Teresa García Domínguez, "A Emigración Galega a América no Século XX: O caso peruano", en Roberto Irimia-Vásquez y Juan Francisco Froján Fontán (coordinadores), I Encontros Galicia-América, Santiago de Compostela, CIHUGA, 1992, págs. 27-29.

${ }^{10}$ María Teresa García Domínguez, "Aproximación ó estudio da emigración galega da "Costa da Morte” cara a Perú na segunda metade do século XX (1940-1970)”, Estudios Migratorios, 5 (1998), págs. 177-198.

${ }^{11}$ María Teresa García Domínguez, "Outros países de acollida: Chile, Perú”, en Pilar Cagiao Vila (coordinadora), A emigración galega a América do Sur, A Coruña, Hércules de Ediciones, 2013, págs. 304-357.

${ }^{12}$ Cadena migratoria es la transferencia de información y apoyos materiales que familiares, amigos o paisanos que ofrecen a los potenciales migrantes para decidir, o eventualmente, concretar su viaje. Estas cadenas facilitan el proceso de salida y llegada, pueden financiar en parte el viaje, gestionar documentación, empleo y conseguir vivienda. Producen un intercambio de información sobre los aspectos económicos, sociales y políticos de la sociedad de llegada. En este caso la cadena migratoria
} 
pionero de la pesca en Perú. Chouciño Fernández en su publicación de 2010, Sobre las olas: hacia Chimbote ida y vuelta, brinda aproximaciones importantes respecto a la migración de los gallegos de la Costa da Morte hacia el puerto de Chimbote en la costa peruana, la forma como estos lograron asociarse y narra algunas causas del retorno a Galicia de la mayoría de ellos ${ }^{13}$.

Gracias a estas dos últimas autoras, se ha podido obtener y recuperar información más actualizada sobre la emigración gallega hacia el Perú, y específicamente hacia algunos puertos en la costa del Océano Pacífico, pues lugares como Chimbote, Callao, Ilo, Chancay, Samanco, Salaverry, entre otros, se convirtieron en destinos migratorios de cientos de gallegos de la Costa da Morte ${ }^{14}$.

El trabajo que desarrollamos es un aporte a estos y se inicia en los años cincuenta del siglo pasado, cuando se estableció una red migratoria muy significativa entre

está restringida al grupo doméstico, el que a su vez, traspasa los límites de la unidad residencial. Estas cadenas migratorias a su vez forman parte de una estructura mayor: las redes migratorias, que son más extendidas y afianzadas, desarrollan una dinámica propia, que incluso puede desprenderse de los estímulos y desestímulos de la sociedad de destino (como por ejemplo la demanda o no de mano de obra). Estas redes, dependiendo de su función, se tratan de redes internas o internacionales. Las redes no son espontáneas ni efímeras, cambian y se complejizan con el tiempo debido a las relaciones que genera la entrada de otros actores dentro de su estructura. En: Claudia Pedone, Tu siempre jalas a los tuyos. Cadenas y redes migratorias de las familias ecuatorianas hacia España, Barcelona, Universitat Autònoma de Barcelona, Facultad de Filosofia i Lletres, Departament de Geografía, págs. 108-109, 2003.

Para un mayor entendimiento de la propuesta teórica de cadenas y redes migratorias: Mark Granovetter, Getting a Job: A Study of Contacts and Careers, Chicago, University of Chicago Press, 1995; Margaret Grieco, Keeping it in the family: social networks and employment chance, London and New York, Tavistock Publications, 1987 y Claudia PeDone, "Cadenas y redes migratorias: propuesta metodológica para el análisis diacrónico-temporal de los procesos migratorios", Empiria. Revista de Metodología de Ciencias Sociales, 19 (2010), págs. 101-132.

${ }^{13}$ Ana Chouciño FernandÉz, "Sobre las olas: hacia Chimbote ida y vuelta", en XIV Encuentro de Latinoamericanistas Españoles: congreso internacional, Santiago de Compostela, Universidade de Santiago de Compostela, 2010.

${ }^{14}$ Chimbote es una ciudad en la costa noroccidental del Perú, a $431 \mathrm{~km}$. de la capital, Lima. Es capital de la Provincia de Santa, en el extremo noroeste del departamento de Ancash, ubicada a orillas del Océano Pacífico (bahía El Ferrol) y es la novena más poblada del Perú. Según el censo de población de 2007, tenía cerca de 300 mil habitantes. Es uno de los puertos más importantes del Perú por su intensa actividad portuaria, sede de industrias siderúrgicas y pesqueras, además de ser un eje comercial.

Callao es una Provincia Autónoma y principal puerto del Perú, ubicado en la costa central muy cerca de Lima.

Ilo es un puerto ubicado en la costa sur del Perú, en el departamento de Moquegua.

Chancay es uno de los 12 distritos que conforman la provincia de Huaral, en el departamento de Lima y a $65 \mathrm{~km}$. al norte de la capital.

Samanco es uno de los 11 distritos que conforman la provincia de Santa, en el departamento de Ancash. Salaverry es una localidad de la costa norte del Perú, a $14 \mathrm{~km}$. al sur de la ciudad de Trujillo. Es capital y único centro poblado del distrito del mismo nombre. Pertenece a la provincia de Trujillo, departamento de La Libertad. 
Malpica de Bergantiños ${ }^{15}$ en Galicia y el puerto peruano de Chimbote. Migración que tuvo motivaciones políticas cuando en su primera etapa se dirigió hacia Chile, devino posteriormente en causas económicas, proceso que se detuvo en los años setenta, fruto de diversas circunstancias que explicaremos brevemente. Producto de aquel movimiento de población, actualmente varios peruanos de nacimiento con nacionalidad española viven en Malpica de Bergantiños y en La Coruña, así como algunas mujeres peruanas vinieron a esta parte de Galicia a vivir con sus esposos gallegos. Hemos obtenido los relatos de algunos malpicáns de avanzada edad, que vivieron y trabajaron durante su juventud en Perú.

\section{Exilio durante la Guerra Civil y llegada al Perú}

Durante la Guerra Civil, Galicia fue una de las regiones de España dominadas rápidamente por el bando nacionalista. Fue en este trance, que una dura y sangrienta represión se desató sobre algunos puertos de la costa coruñesa de tradición anarcosindicalista ${ }^{16}$. Algunos jóvenes gallegos se vieron obligados a huir. Así es como en la tarde del 29 de agosto de 1938, a bordo de la embarcación pesquera "San Adrián", 26 hombres se embarcaron en una travesía arriesgada hacia la costa francesa. Las motivaciones obedecían a cuestiones políticas, el negarse a combatir obligatoriamente para el bando franquista y otros pocos, quizás iban como aventureros o queriendo salir de la rutina de su población ${ }^{17}$. Sin embargo, parece que las dos primeras fueron las causas principales. A decir de Celestino Garrido Garrido, quien fue uno de los tripulantes del "San Adrián":

Fue una aventura tan grande que si nos agarran, no quedaba ninguno con vida, nos mataban a todos. Y además, ibamos a hacer una travesía que no conocíamos, aunque yo estaba casi seguro de que iba a llegar bien ${ }^{18}$.

\footnotetext{
${ }^{15}$ El Ayuntamiento de Malpica de Bergantiños está localizado al noroeste de la provincia de A Coruña, en la comarca de Bergantiños, en la mítica y afamada Costa da Morte. Tiene una extensión de 60,5 $\mathrm{km} 2$, y en la actualidad cuenta con más de seis mil habitantes. Malpica sigue siendo uno de los puertos de bajura más importantes del litoral gallego. La pesca es una de las actividades económicas de sus pobladores, aunque también existen actividades agropecuarias e industrias del barro.

${ }^{16}$ Santiago Romero, "La Gran Odisea", La Opinión A Coruña [en línea], disponible en <www. laopinioncoruna.es/estaticos/domingo/20070902/domingo.html> [Consulta: 06/05/2012].

17 Televisión de Galicia, “A Aventura de Malpica no Perú”, Galicia no Mundo, [documento audiovisual], [s.1.], Televisión de Galicia, 1989.

${ }^{18}$ Ídem.
} 
Se cuentan con algunos datos sobre tres embarcaciones de pesca que usaron algunos malpicáns para llegar a Francia en fechas diferentes: la "Rocío", "Ciudad de Montevideo" y el "San Adrián", y es de este último del que se tiene mayor información. La travesía duró más de tres días, y sus pasajeros hicieron su viaje en condiciones muy precarias, sin víveres, ni agua, alimentándose solo con pan; además que no tenían cartas de navegación. Sin embargo, Celestino Garrido había memorizado parte de ella:

Había mirado mucho el mapa y la carta marítima. Había mirado mucho y más o menos, sabía que rumbo debía llevar ${ }^{19}$.

Aquella embarcación estuvo capitaneada por Francisco Fariña Chouciño y entre algunos de su tripulantes estuvieron el mencionado Celestino Garrido, su hermano Bernardino ${ }^{20}$, José Castro, entre otros. Así, llegaron a la Bretaña francesa, exactamente al puerto de Brest, tras atravesar un temporal en el Golfo de Vizcaya y probablemente tras recibir provisiones de un submarino nazi que los confundió con náufragos.

Poco más de 60 fueron los malpicáns que huyeron en las tres embarcaciones mencionadas. Un periodista, Víctor Rodríguez, quien llegó a dialogar con algunos de ellos, escribió:

O trece de agosto de 1938 escapara da guerra, xunto con outros 26 homes, a bordo do San Adrán, co seu motro Líster de 20 cv. Case un mes despois, o 31 de agosto, marchou a Rocío con outros 29 homes. E un ano antes, 028 de xuño do 1937, marcharan xa 11 homes a bordo do Montevideo, unha motrora de 12 metros de eslora e un motro Badwin de $20 \mathrm{cv}$.

Aunque no hay una coincidencia de la fecha de partida del "San Adrián" entre los trabajos citados anteriormente, es importante resaltar el hecho de que siendo más de 60 personas y en su mayoría varones los que huyeron de Malpica de Bergantiños, esta es una cantidad significativa teniendo en cuenta que hablamos de

\footnotetext{
19 Ídem.

${ }^{20}$ Bernardino Garrido, tenía como apodo el Xudío. Fue padre del más afamado malpicán en el Perú, Celestino Garrido Pose.

${ }^{21}$ Ana Chouciño Fernandéz, "Sobre las olas: hacia Chimbote ida y vuelta", en XIV Encuentro de Latinoamericanistas Españoles: congreso internacional, Santiago de Compostela, Universidade de Santiago de Compostela, 2010, pág. 939.
} 


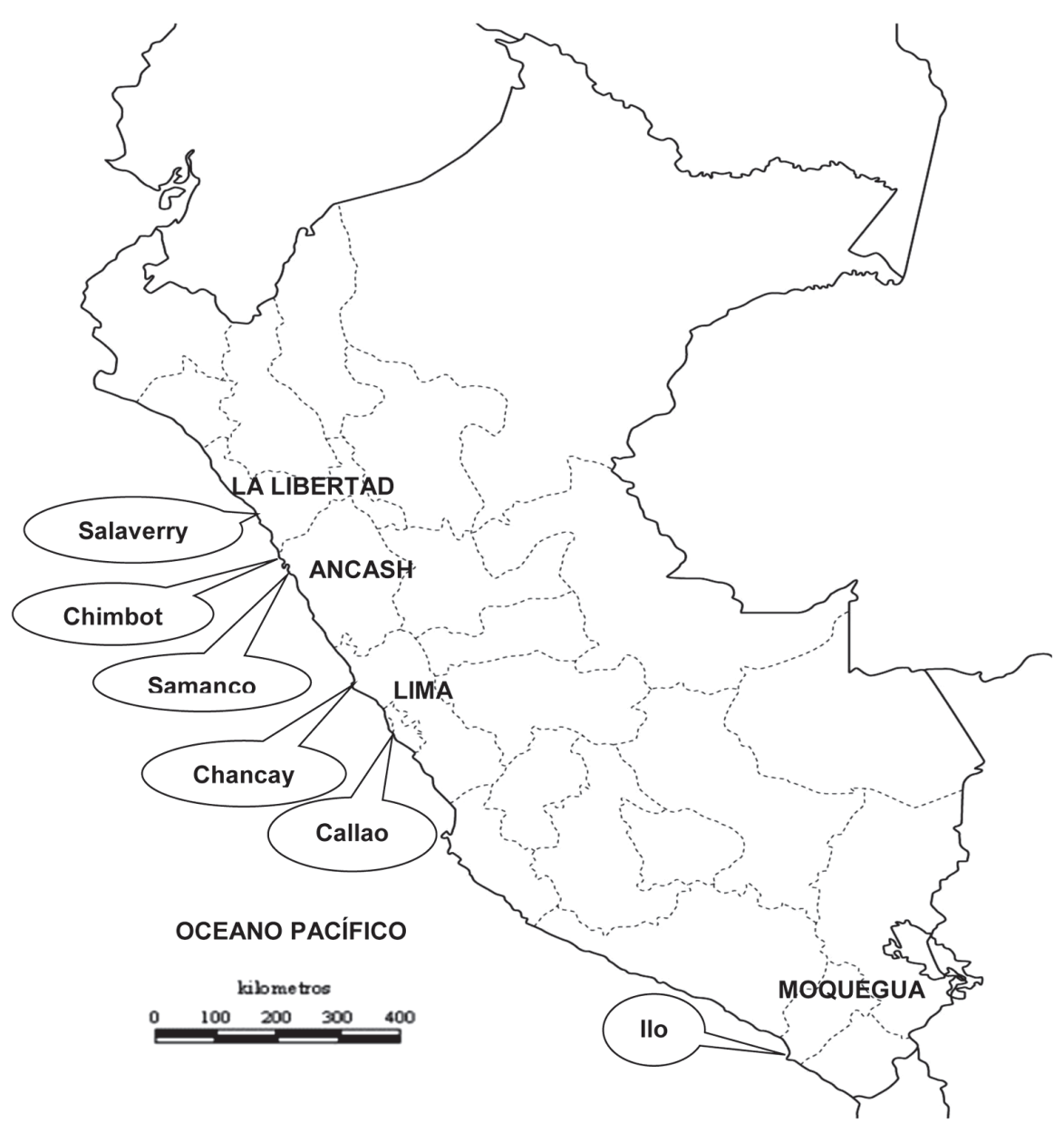

Mapa 1. Localización de los puertos y pueblos de destino de los gallegos que migraron al Perú en la segunda mitad del siglo pasado.

(Diseño del autor)

un pequeño Concello que en 1930 tenía 6.261 habitantes. Tan arriesgada travesía hacia Francia fue un hecho que no pudo pasar desapercibido.

Llegados a Francia algunos de ellos se quedaron en este país, otros decidieron regresar a España (Cataluña) y seguir combatiendo por la República hasta el final de la Guerra Civil y volver nuevamente a Francia. Sin embargo, otros terminaron en campos de concentración alemanes tras haber pasado meses en campos 
de refugiados franceses ${ }^{22}$. Los más afortunados de aquellos gallegos pudieron embarcarse hacia Chile en 1939. De esta manera, ya habría emergido entre estos primeros malpicáns una tendencia (forzada o no) a la migración, que ampliaría sus posibilidades para una futura llegada a Perú, como lo veremos más adelante.

En aquel entonces, el escritor Pablo Neruda, militante del Partido Comunista de Chile, que pocos años atrás había sido cónsul de su país en Barcelona y en Madrid, tuvo la iniciativa y asumió la responsabilidad de realizar los trámites necesarios y llevar a los exiliados españoles desde Francia hacia este país, por lo que fue nombrado cónsul delegado en París en 1939. Así el gobierno chileno, no sin antes tener algunas resistencias, realizó el Servicio de Evacuación de Refugiados Españoles y fletó un barco, el "Winnipeg", donde viajaron más de 2.000 españoles, entre los que figuraban doce malpicáns de apellidos Chouciño, Verdes, Garrido, Alfeirán, Arcay, Novo, entre otros, los mismos que habían sido compañeros durante la huida de Malpica. Para esto, se hizo una selección entre los españoles que arribarían a Chile, ello en función de sus perfiles profesionales ${ }^{23}$. Los exiliados malpicáns, pescadores y hombres de mar decidieron embarcarse, conocedores de las labores que podían hacer en el litoral de aquel país:

\begin{abstract}
Nosotros sabíamos que Chile tenía mucho mar y no dudamos en embarcar. Además de que eran los pasajes más baratos. Entre los exiliados había diferencias: los dirigentes politicos fueron a Rusia pagados por el gobierno de Stalin, los intelectuales y los republicanos de clase media se fueron, pagándolo de su bolsillo, a México. A Chile fuimos los más pobres: los marineros (Celestino Garrido) $)^{24}$.
\end{abstract}

El 04 de agosto de 1939 el "Winnipeg" partió del muelle de Trompelout, cercano a Burdeos y arribaron al puerto de Arica, 26 días después de salir de Francia, formando los malpicáns una pequeña colonia en aquel lugar ${ }^{25}$. Por aquel entonces un gallego de Corcubión, Benigno Lago, jugó un rol principal para que los malpicáns migraran otra vez, ahora hacia el Perú.

Lago había emigrado a Argentina en 1920 con su esposa e hizo fortuna en la Patagonia, instalándose en el lugar denominado Río Gallegos. En 1931 regresó a

\footnotetext{
22 Ídem.

${ }^{23}$ María Teresa García Domínguez, “Aproximación ó estudio da emigración galega da "Costa da Morte” cara a Perú na segunda metade do século XX (1940-1970)”, Estudios Migratorios, 5 (1998), pág. 187 y Ana Chouciño Fernandéz. "Sobre las olas: hacia Chimbote ida y vuelta...”, págs. 939-940. ${ }^{24}$ Santiago Romero, "La Gran Odisea", La Opinión A Coruña [en línea], disponible en <www. laopinioncoruna.es/estaticos/domingo/20070902/domingo.html> [Consulta: 06/05/2012].
} 
España con sus hijos, para luego volver a emigrar hacia el Perú donde estableció negocios en la explotación minera y en la industria de la piel de lobo de mar, y posteriormente, junto con otros socios peruanos incursionó en la industria pesquera llegando a tener 6 fábricas de conservas de pescado. Una vez enterado de que en Chile vivía un grupo de malpicáns, fue en su busca y les ofreció empleo en sus fábricas de Ilo y Chimbote ${ }^{26}$. Así, fueron arribando al Perú ese primer grupo de gallegos exiliados iniciándose una red migratoria que se prolongó hasta mediados de los años setenta del siglo pasado, y llegando a tener algunos de ellos, una destacada participación en la industria pesquera. Muchos se iniciaron como simples empleados u obreros, y con el transcurso de los años, varios se convirtieron en dueños de barcos y en grandes empresarios pesqueros:

\begin{abstract}
Moitos deles traballaron para Benigno Lago, pero pouco a pouco foron desligándose e montando os seus propios negocios, comprando barcos e montando fábricas, dando lugar nalgúns casos a importantes imperios económicos como o de Celestino Garrido Pose, que chegou a ser vicecónsul español en Perú27.
\end{abstract}

\title{
3. Chimbote: otra Malpica a orillas del Pacífico ${ }^{28}$
}

Desde los años cuarenta del siglo pasado en el puerto peruano de Chimbote, ya había cobrado impulso la explotación pesquera, aunque la principal actividad de su puerto era la embarcación de azúcar para la exportación, cuya producción se realizaba en algunas haciendas cercanas de la costa. Se podían extraer de sus aguas cercanas, bonitos (túnidos), sardinas, cojinovas y anchoas ${ }^{29}$. Algunos de

\footnotetext{
${ }^{25}$ Mónica Sabbatiello, "La lenta agonía de los indianos de Malpica (I). El cólera casi arruina a las industrias gallegas en Perú", El Correo Gallego (25 de marzo de 1991), pág. 13 y Televisión de Galicia, "A Aventura de Malpica no Perú", Galicia no Mundo, [documento audiovisual], [s.1.], Televisión de Galicia, 1989. Es importante anotar que otros autores, nombran como puerto de llegada a Valparaíso, Santiago Diana MANDí́, "El ayer de Malpica pasa por Perú", El País [en línea], disponible en <www. elpaís.com/diario/2010/01/07/galicia/1262863099_850215.html> [Consulta: 16/04/2012].

${ }^{26}$ María Teresa García Domínguez, "Aproximación ó estudio da emigración galega cara a Perú...”, págs.185-186.

27 Ídem., págs. 187-188.

${ }^{28}$ Al respecto, Televisión de Galicia, "A Aventura de Malpica no Perú", Galicia no Mundo, [documento audiovisual], [s.1.], Televisión de Galicia, 1989:

Fue como así, desplazándose de nuevo fijaron sus residencias en el Callao, puerto de Lima, Ilo, Chancay, Samanco, pero sobre todo en Chimbote, a $400 \mathrm{Km}$. al norte de la capital, «de aquella pequeña ciudad que los gallegos hicieron otra Malpica que miraba al Pacifico».

${ }^{29}$ Las cojinovas, son peces marinos de la familia de los Centrolophidae y que se distribuyen desde el Ecuador hasta la costa central de Chile. En el Perú a la anchoa, se le denomina anchoveta.
} 
estos ejemplares eran exportados hacia laboratorios norteamericanos para la industria farmacéutica, pero las anchoas carecían de valor y no se consumían ${ }^{30}$.

Fue a partir de los años cincuenta, cuando verdaderamente se industrializa el sector pesquero en este puerto $^{31}$. La anchoa, que anteriormente no tenía importancia económica alguna, se convirtió en la principal materia prima para la fabricación de la harina de pescado. Así, se empezaron a implementar grandes fábricas y en pocos años el Perú llegó a ser el primer productor mundial de harina de pescado. Este enclave económico, que se desarrolló principalmente en Chimbote, atrajo a muchos inmigrantes rurales hacia esta ciudad y también a muchos extranjeros:

Había muchas fábricas y armadores de todas las nacionalidades. Corría el capital extranjero. En Chimbote vivíamos separados por colonias: los peruanos, los italianos, los norteamericanos, los malpicanos... Había hasta armadores yugoslavos. Hay que vivirlo para saber lo que fue aquello. Había muchísimos barcos. El tráfico era incesante todos los días. Pescando, desembarcando y volviendo a pescar. Era un río de pescado (Manuel Suárez) ${ }^{32}$.

Tanto la migración interna como la extranjera que llegó a Chimbote, la convirtió en una ciudad culturalmente muy heterogénea, con muchas tensiones raciales y sociales, las que también se agudizaban con la explotación de la numerosa mano de obra que provenía de la sierra del Perú. Este puerto que llegó a ser tan rico, fue además una ciudad de fuertes contrastes y desigualdades entre los extranjeros y los peruanos ${ }^{33}$.

Una vez iniciado el despegue de la industria pesquera en Chimbote, se activó una red migratoria entre este puerto y la Costa da Morte en Galicia (ver Gráfico $\mathrm{N}^{\mathrm{o}}$ 1). Entre algunos gallegos que empezaron a contratar e incluso a trasladar a muchos de ellos hacia el Perú, tenemos al mismo Benigno Lago, quien viajó a Galicia en 1946 para traer a su familia y a algunos vecinos del lugar, principalmente de Fisterra, para que trabajen en sus fábricas. García Domínguez lo señala de esta manera:

\footnotetext{
30 María Teresa García Domínguez, “Aproximación ó estudio da emigración galega cara a Perú...”, pág. 186 y Ana ChouciÑo Fernandéz, “Sobre las olas: hacia Chimbote ida y vuelta...”, pág. 941.

${ }^{31}$ La gran riqueza del mar peruano, se debe a los siguientes factores: la frialdad de sus aguas, la abundancia del fitoplancton (vegetales y plantas microscópicas) y del zooplancton (microscópicos organismos acuáticos), la amplitud del zócalo continental y la convergencia de las corrientes peruana o de Humboldt y la del Niño.

32 Santiago Romero, "La Gran Odisea", La Opinión A Coruña [en línea], disponible en <www. laopinioncoruna.es/estaticos/domingo/20070902/domingo.html> [Consulta: 06/05/2012].

33 Ana Chouciño Fernandéz, "Sobre las olas: hacia Chimbote ida y vuelta...”, págs. 941-943.
} 
En 1946 marcharon con Benigno Lago, a súa muller e dous fillos, Jaime, casado con Josefa Rodríguez, e Alberto. En 1947 emigra o seu fillo Salvador coa súa esposa M. ${ }^{a}$ Ángeles Cordo, seu primo Benigno Abella, coa muller e dous fillos, un sobriño; Víctor Lado Pomiano, que se reunirá coa súa muller Carmen Mosquera e dous fillos en 1952. En 1950 emigra José Martínez López e Luis Santiago, coa súa muller Amelia Fernández e unha filla (en Perú naceron dous fillos máis), e un ano despois seua irmán Franciso, que casará por poderes con Dolores López Soliño, que se reunirá co seu home en 1960. En 1951 emigran os irmáns Silva Canosa, José e Celestino, e Franciso Vásquez Candamo, que en 1955 levará a dous irmáns, Bernardino e Manolo, coas súas respectivas mulleres e fillos. Tamén marcha neste ano Manuel Cacheiras, que mandará chamar ó seu fillo Carlos en 1964, e que, casado cunha peruana, aínda reside en Lima, e José Outes. En 1953 emigra Manuel García Lagoa, que levará a seu irmán Saturnino en 1960 e tamén emigrarán as súas respectivas esposas, tendo fillos nacidos alá. En 1955 emigra Feliciano García coa muller e seis fillos. Desde Fisterra emigra José Fraga Insua, que mandará chama-la súa muller e dez fillos, con algún sobriño, etc. ${ }^{34}$

Sin embargo, es probable que otros malpicáns como Celestino Garrido, José Castro, Pedro Chouciño y su padre ${ }^{35}$, también facilitaran la llegada de sus familiares y amigos. Es importante indicar que los gallegos no solo emigraron de Malpica hacia las costas peruanas y Chimbote, pues también procedían de Corcubión, Cee y Fisterra. Durante la década de los años cincuenta y sesenta, cuando fue incrementando la colonia gallega en Chimbote, llegaron más inmigrados de la provincia de Pontevedra, especialmente de Marín, también de Ourense, de Caión (A Laracha), O Cariño y Laxe de la provincia de A Coruña, quienes antes habían estado residiendo en Argentina y Uruguay ${ }^{36}$.

Los malpicáns fueron llegando a Chimbote en la medida que la industria pesquera fue expandiéndose y se necesitaba más mano de obra. El Perú fue nue-

\footnotetext{
${ }^{34}$ María Teresa García Domínguez, “Aproximación ó estudio da emigración galega cara a Perú...”, pág. 188.

${ }^{35}$ Televisión de Galicia, “A Aventura de Malpica no Perú”, Galicia no Mundo, [documento audiovisual], [s.1.], Televisión de Galicia, 1989.

${ }^{36}$ María Teresa García Domínguez, "Aproximación ó estudio da emigración galega cara a Perú...”, pág. 188 y Televisión de Galicia, “A Aventura de Malpica no Perú”, Galicia no Mundo, [documento audiovisual], [s.1.], Televisión de Galicia, 1989.
} 
vamente percibido por estos inmigrados ${ }^{37}$, como un nuevo El Dorado. Ahora la riqueza no era mineral, ni metal alguno; había que extraerla del fondo del mar. Pedro Chouciño relató brevemente años atrás, la manera cómo la actividad pesquera en este puerto fue creciendo y evolucionando:

\begin{abstract}
Hay dos tiempos que Chimbote fue feliz. Primero fue con el bonito. Nosotros empezamos pescando bonito cuando no había nadie que lo quisiera y había que tirarlo al mar. Asi empezamos en Chimbote... Después vinieron los años gordos del bonito, cuando se ganó plata (dinero) con el bonito, los años 55, 56 hasta 58. Esos fueron buenos años para la pesca, pero después, luego anchoa. Anchoa empezó en los años 58, 59. A medida que iban pasando los años, las lanchas iban quedando chicas, cada vez las lanchas eran más grandes. Se hacían lanchas más grandes, se necesitaba más personal ${ }^{38}$.
\end{abstract}

Un gallego que destacó entre los muchos que llegaron al Perú, y de los que más fortuna acumuló, fue Celestino Garrido Pose, quien llegó a ser vicecónsul de España en el Perú. Llegó a Chimbote en 1951 y empezó a trabajar en la pesca del bonito y de la cojinova que iba destinada al mercado de Lima, donde se le procesaba para conservas. En 1957 Garrido llegó a tener su propia fábrica de harina de pescado, donde trabajaron 600 personas. En 1963 ya era dueño de 7 lanchas de 230 t. cada una, su fábrica tenía una flota de 25 barcos con una capacidad en bodegas de 3000 t. y esta trabajaba con una capacidad de $9000 \mathrm{t}^{39}$.

Chimbote prosperó y con ello también muchos de los gallegos que llegaban a trabajar allí. En 1960 esta ciudad ya contaba con 160.000 habitantes, 40 fábricas procesadoras de pescado, una flota de 800 barcos que podían desembarcar en su puerto más de 200.000 toneladas de peces para sus fábricas y los gallegos llegaban con contratos de trabajo y reclamados por sus familiares ${ }^{40}$. El sueldo que éstos

\footnotetext{
${ }^{37}$ Estamos usando en esta parte la categoría de inmigrados y emigrados, de acuerdo a la propuesta de Abdelmalek Sayad, para ubicarnos espacialmente y temporalmente en el proceso de inmigración. Abdelmalek SAYAD, La Doble Ausencia. De las ilusiones del emigrado a los padecimientos del inmigrado, Barcelona, Anthropos Editorial, 2010.

38 Televisión de Galicia, “A Aventura de Malpica no Perú”, Galicia no Mundo, [documento audiovisual], [s.1.], Televisión de Galicia, 1989.

${ }^{39}$ Mónica Sabbatiello, "La lenta agonía de los indianos de Malpica (I). "El cólera casi arruina a las industrias gallegas en Perú", El Correo Gallego (25 de marzo de 1991), págs. 12-13 y Televisión DE Galicia, "A Aventura de Malpica no Perú", Galicia no Mundo, [documento audiovisual], [s.1.], Televisión de Galicia, 1989.

${ }^{40}$ María Teresa García Domínguez, "Aproximación ó estudio da emigración galega cara a Perú...", pág. 190 y Ana Chouciño Fernandéz, "Sobre las olas: hacia Chimbote ida y vuelta...", pág. 941.
} 
percibían era más del doble de lo que podían ganar en Galicia y esto les permitió a muchos de ellos ahorrar y enviar periódicamente remesas hacia sus hogares, además edificaron y fundaron un centro social para la colonia gallega en este puerto.

Es necesario mencionar que como en todo proceso migratorio, en este caso los inmigrados malpicáns en Chimbote, eran de distintas procedencias sociales y perseguían objetivos diferentes, aunque muchos fueran de las mismas familias. Algunos viajaron con una actitud empresarial, buscando aprovechar la gran bonanza pesquera en el Perú, y lograron ser patrones, armadores y dueños de varios barcos de pesca y fábricas. Otros buscaban objetivos inmediatos como un mejor sueldo, mejorar sus condiciones de vida o simplemente construir su vivienda. Los proyectos migratorios fueron disimiles entre los cientos de malpicáns que vivieron en ese puerto peruano ${ }^{41}$.

Dos entrevistados nuestros, aunque emigraron en fechas distintas, el primero en 1953 y el segundo a finales de 1962, coincidieron en señalar que los motivos de sus migraciones fueron la pobreza y las malas condiciones de vida. El primero nos dijo que había bastante miseria a raíz de la Guerra Civil y lo explicó de la siguiente manera:

No me daba pena y tristeza al irme... Porque en esa época aquí en España recién terminada la Guerra Civil y la Segunda Guerra Mundial se pasaba... Entonces todo el que tenía que emigrar, se iba a América, Uruguay, Chile, Argentina ... Todo el que tenía posibilidad de largarse, se largaba (Pepe Garrido. Fue armador de un barco de pesca en Chimbote).

El otro informante, corrobora las malas condiciones de vida que muchas familias atravesaban en esta parte de Galicia. Nos relató que se dedicaba día y noche a la pesca de nécoras y percebes, pero que con dos hijos menores, una casa en construcción con la consiguiente deuda bancaria y en un invierno muy fuerte que hizo disminuir mucho la pesca, se vio en la necesidad de migrar al Perú: así no se podía estar... Y me fui al Perú, nos dijo.

\footnotetext{
${ }^{41}$ Se define como proyecto migratorio a los objetivos vitales perseguidos por los migrantes. Cualquiera que sea el grado de formalización de estos proyectos y los motivos que impulsan a las personas a vivir en otros países (aunque los económicos son los principales, también existen los familiares o afectivos, la búsqueda de conocimiento o de aventuras, los políticos o ideológicos y otros muy diversos), los migrantes pueden chocar con varios impedimentos para la realización de lo que se proponen: Daniel LA PARRA CASADO, "Violencia estructural y migración: Las instituciones sociales en España", en Francisco Hidalgo (ed.), Migraciones. Un juego con cartas marcadas, Quito, Ediciones Abya-Yala, 2004, pág. 233.
} 
Gráfico 1. Cronograma de la llegada de algunos inmigrados gallegos a

Chimbote. Cadena migratoria familiar activada por Benigno Lago.

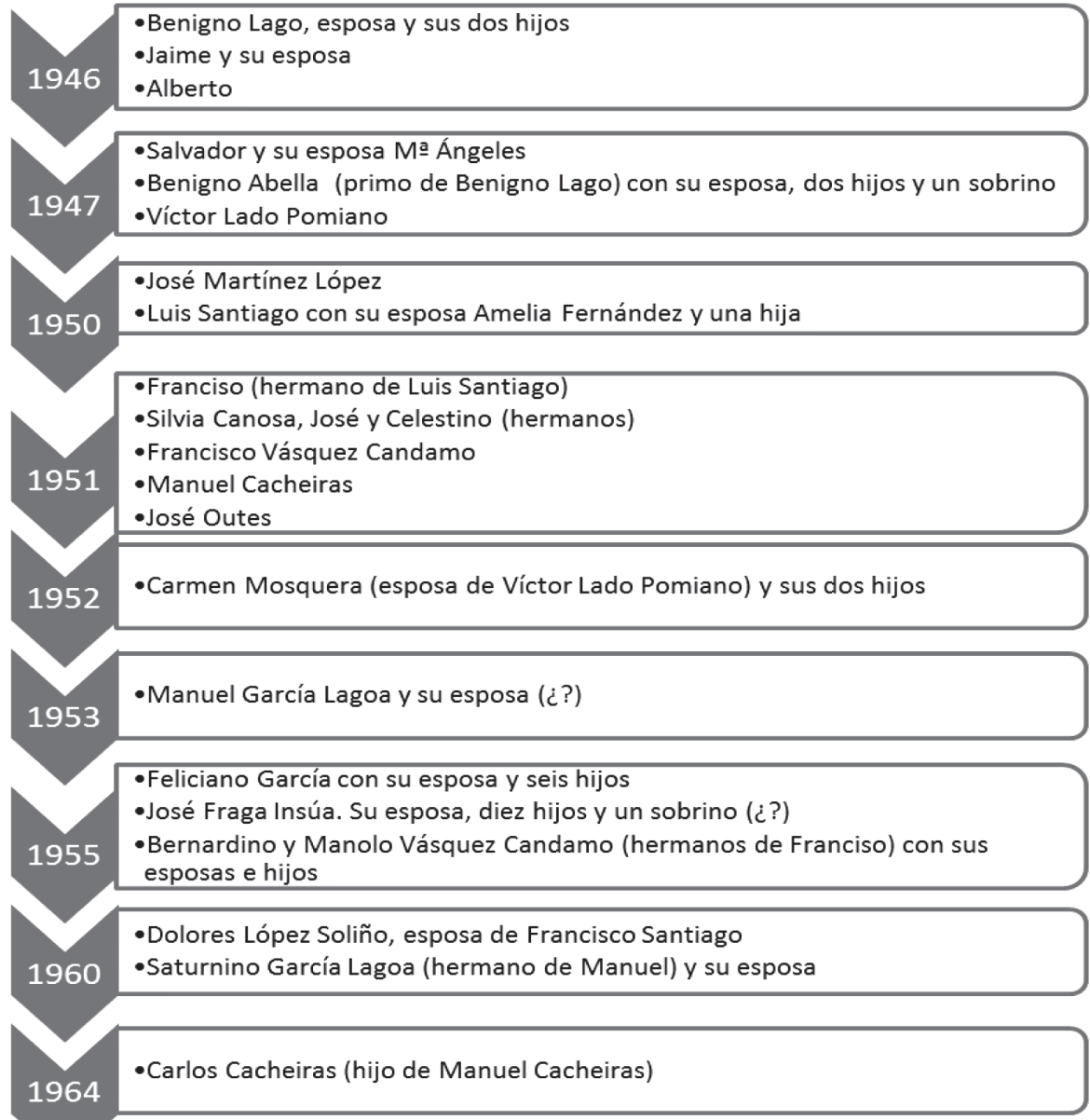

Este mismo señor, quien trabajó como marinero en Chimbote entre 1962 y 1964 nos relató que en una semana podía ganar desde S/. 4.000 hasta S/. 6.000, que en aquel tiempo era mucho dinero ${ }^{42}$. En aquellos años S/. 1 equivalían a 2,2 pesetas, US\$. 1 (un dólar americano) cerca de S/. 27, y en España 120 pesetas

${ }^{42}$ Durante esos años la moneda peruana fue el Sol y su abreviatura es S/. 
equivalían a US\$ 1. Para muchos malpicáns el envío de remesas de dinero a sus familias en Galicia, se constituyó en una obligación y objetivo permanente. Este señor nos relató esta transferencia de dinero desde Chimbote hasta Malpica de Bergantiños de la siguiente manera:

\begin{abstract}
Y yo agarraba así... Si mañana hay que enviarle plata a la mujer. Yo mandaba de dos en dos semanas... Yo le mandaba un día viernes o un día lunes. Entonces un día antes iba a casa de Carmelas y le decía a Carmela (gallega inmigrada en Chimbote): "Manda esta plata a mi señora”. Entonces Carmela se iba al Banco Popular, al que le llamaban Don Pepe (un señor que trabajaba en este banco), era chino, que tenía un bar grandazo allí, el "Chimú”... Iba allí y le daba un cheque por tantos dólares... para cobrar aquí mi mujer. El cheque venía a España, al banco "Banesto". Le llamaban a mi señora y mi señora lo cambiaba (por pesetas)... A Malpica llegaba el dinero, al banco, el cheque llegaba al banco... Comparaba los dólares en el Popular y me daban los cheques en dólares (Segundino Cuevas. Trabajó como marinero en Chimbote).
\end{abstract}

Un malpicán que migró al Perú en 1952 y que llegó a ser un próspero empresario pesquero en Chimbote (dueño de 5 barcos) nos dijo que no partió de Malpica porque ganaba poco dinero, pues tenía un buen salario por su trabajo en el mar. Su esposa mencionó: fuimos porque éramos muy jóvenes y nos fuimos a la aventura. En las siguientes declaraciones de nuestro entrevistado se relata un afán empresarial:
Yo no fui por hambre eh... Yo fui porque quería ser más. Yo quería ser industrial. Me parecía que me había estancado aquí... Pero yo sabía que si mi padre no tenía barco, yo nunca iba a hacer nada aquí... aquí solamente vamos a estar de criados de éstos y yo tengo capacidad para defender un barco como ellos... Había que ir donde habia más pasta (Humberto Verdes).

Ninguno de nuestros entrevistados manifestó causas políticas para su migración, las que si fueron de los primeros malpicáns asentados en Chimbote. Sea por uno u por otro motivo, la decisión de emigrar hacia el Perú durante aquellos años respondían a objetivos personales, familiares, económicos y sociales que en los distintos niveles apuntan a la consecución de un bienestar familiar y un desarrollo que los gallegos no percibían por aquellos años en Malpica. 


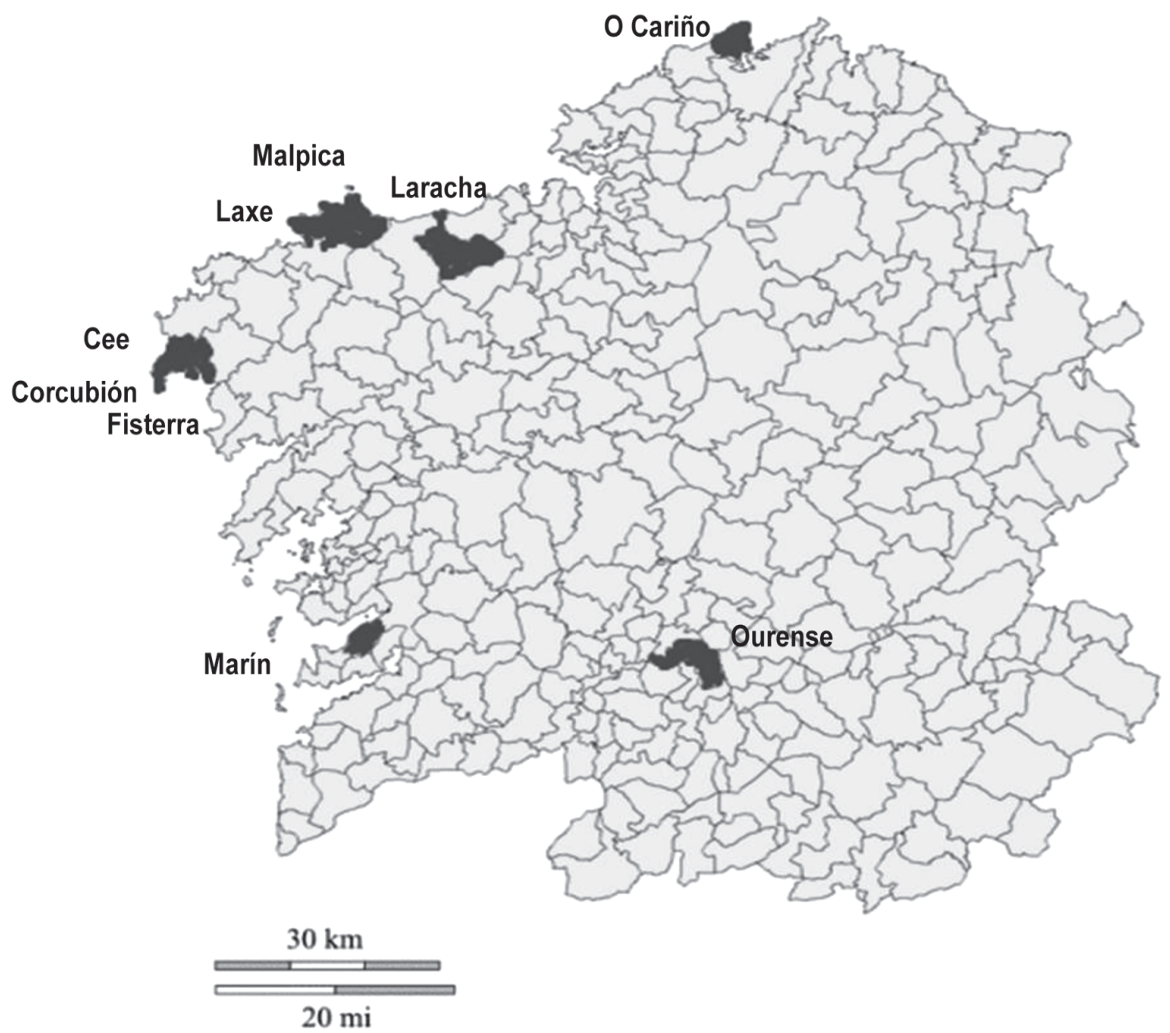

Mapa 2. Principales Concellos de origen de los gallegos que emigraron a puertos peruanos a mediados del siglo pasado.

(Elaboración propia)

\section{La sociedad española de BeneficienCia en Chimbote}

$\mathrm{Al}$ igual que en otros destinos migratorios de América, los gallegos fundaron y edificaron un centro social en Chimbote. Así, el 16 de octubre de 1960 fundaron la "Sociedad Española de Beneficencia", en cuya primera reunión se acordó que:

...Se tenía el propósito muy elogiable y trascendente de haberse congregado para fundar y constituir legalmente la Sociedad Española de Beneficencia de Chimbote, con fines de protección mutua y netamente sociales y no solo en bien de los españoles, sino también 
de los peruanos y demás moradores de este país. Sus objetivos iniciales fueron de auxiliar y socorrer a los socios en caso probado de enfermedad, desgracia familiar o de extrema pobreza ${ }^{43}$.

Humberto Verdes quien también fue presidente de esta Sociedad, nos relató en una entrevista la constitución de esta:

La Casa de España empezó como una Beneficencia... Entonces habia mucha pobreza. Cuando llegamos habia mucha pobreza porque no se ganaba.

No había anchoa en ese tiempo tampoco (intervino su esposa)

No se ganaba porque no había barcos grandes. Había redes de cortinas. Iban cuatro pescadores, pero el resto no. No habia gente, no llegaba aún gente de la sierra ¿no? Porque cuando llegamos habia 12 mil habitantes en Chimbote más o menos y cuando venimos (a Malpica) habia 200 mil. Entonces a la gente que nosotros veíamos pobres, teníamos ahí un médico que era español, que estuvo con los indios en la selva, que vino para Chimbote junto a los españoles. Y ese médico a la gente pobre de alli y que andaba por la calle, unos eran cojos, los otros... Los atendíamos nosotros... Y después de ahi pasó a ser la Casa de España. La inauguramos, que vino el cónsul de España a inaugurarla. Y hemos hecho un gran club para los españoles, con entrada a los peruanos por supuesto. Teníamos muchos amigos, médicos, los policías, toda la gente, los patrones de pesca que trabajaban con nosotros... Cuando había una fiesta se abrian las puertas a quienes quisieran entrar y está ahi todavía...

Primero estuvo ubicada en un local provisional, pero posteriormente decidieron comprar una parcela para edificar un lugar en el que reunirse. Este terreno era amplio y está situado en el No 423 de la calle Malecón $\mathrm{Grau}^{44}$. En este lugar se construyó un edificio llamado "La Casa de España en Chimbote", más conocida como "El casino español", el que se construyó con la aportación de todos los armadores y marineros gallegos. Para lograr esto, bajo previo acuerdo, los armadores donaban el dinero de un día de pesca de la semana para sufragar los

\footnotetext{
${ }^{43}$ Ana Chouciño Fernandéz, "Sobre las olas: hacia Chimbote ida y vuelta...”, pág. 944.

44 "Vecinos de Malpica quieren revivir la Casa de España en Chimbote", La Voz de Galicia, [en línea], disponible en <www.lavozdegalicia.es/carballo/2009/12/15/0003_8172553.htm> [Consulta: 06/05/2012].
} 
gastos, llegando a aportar cada armador al mes una cantidad muy significativa; y los marineros contribuían con el jornal más elevado de toda la semana ${ }^{45}$.

En "el casino español” se celebraban fiestas, bailes y acontecimientos sociales y se convirtió en el lugar de encuentro, confraternización, recreo y ocio para la comunidad gallega, aunque también era frecuentado por peruanos y otros extranjeros, celebrándose incluso la fiesta de San Pedro, patrón de los pescadores peruanos. Algunos gallegos, conocieron allí a sus esposas. Más allá de la labor asistencial y benefactora, la existencia de la "Casa de España en Chimbote" consolidó un conjunto relaciones sociales de la propia comunidad gallega y española en esta ciudad, que buscaba relacionarse con la sociedad chimbotana.

Este local constaba de un amplio bar, un comedor y varios salones donde se realizaban las fiestas de la comunidad. Su época de esplendor fue desde su edificación hasta inicios de los años setenta, cuando empezaron a retornar casi todos los malpicáns a Galicia o a cambiar de residencia, a causa del terremoto del 31 de mayo de 1970, de la crisis en el sector pesquero, y luego por la política de nacionalizaciones del gobierno militar en el Perú. El local no fue afectado por el terremoto y nunca dejó de funcionar, pero con el transcurrir de los años fue cambiando de dueños y de administradores hasta hace pocos años que fue rehabilitado, a partir de la iniciativa de un peruano hijo de malpicáns, Luis Novo, quien junto a un grupo de descendientes de aquellos gallegos que emigraron hacia el Perú, reinauguraron la "Casa de España en Chimbote" el 30 de marzo del $2010^{46}$. Actualmente funciona como un restaurante donde se sirven platos de comida española y peruana. Asimismo hubo una reestructuración de la "Sociedad Española de Beneficencia" y se eligió una nueva directiva que está actualmente en funciones.

\section{LA INMIGRACIÓN DESDE LOS ACTORES: EXPERIENCIAS Y DISCURSOS}

En los discursos de los malpicáns entrevistados y en el de los familiares de aquellos, hemos obtenido algunos elementos comunes, donde destacan los sentimientos de añoranza, de agradecimiento y respeto hacia los peruanos con quienes

\footnotetext{
${ }^{45}$ Ana Chouciño Fernandéz, "Sobre las olas: hacia Chimbote ida y vuelta...,", pág. 944,Televisión DE Galicia, "A Aventura de Malpica no Perú", Galicia no Mundo, [documento audiovisual], [s.1.], Televisión de Galicia, 1989 y María Teresa García Domínguez, "Aproximación ó estudio da emigración galega cara a Perú...”, pág. 190.

${ }^{46}$ Me permito nombrar a aquellas personas que trabajaron en ello: Maricarmen Pardo (Malpica), Eladio Rosales (Pontevedra), Carmen Alfeirán (Malpica), Lola y María Arcay (Malpica), Pompilio Pose (peruano), Patsy Garrido (peruana, sobrina de Celestino Garrido Pose), Agustín Estévez (Fisterra) y Ana Gloria Chouciño. Información proporcionada por Luis Novo (comunicación telefónica del 19 de mayo de 2012).
} 
trabajaron y compartieron su amistad. Frases como: el Perú es un país maravilloso o el Perú es mi segunda patria, han sido comunes. Incluso uno de ellos recordó muchos detalles de su vida en Chimbote, como el nombre de los peruanos con los que trabajó, y el de los bares y restaurantes que frecuentaba.

También ha sido común encontrar en estos, la referencia al trabajo arduo que realizaban en Chimbote, pues la pesca les demandaba laborar, prácticamente todos los días de la semana:

Yo cuando trabajaba al bonito, trabajábamos los seis días y el domingo por la mañana sacábamos la red para tierra, el sábado por la mañana y la llevábamos a tintar para Coishco ${ }^{47}$... Ahí hay una pampa grande. Alli extendíamos la red, ibamos a remendar la red y después la dejábamos en tinta toda la noche, y el domingo por la mañana deberíamos quitar para sacarla y la embarcábamos el domingo por la tarde. Y el lunes a las tres de la mañana o a las cuatro marchábamos para la mar... Seguido, seguido, asi ah... Yo trabajé mucho, mucho, mucho, muchísimo (Humberto Verdes).

Las relaciones de amistad con los peruanos afloraban en frases como: gente maravillosa los peruanos, o en esta otra: en el Perú me trataron muy bien. Estas recogen un agradecimiento que se plasma en la cordialidad que demuestran nuestros entrevistados con los peruanos que radican actualmente en Malpica, pues hasta bromean con éstos y hablan en una jerga que se usa mucho en Perú. Un malpicán nos dijo que durante su vida en Chimbote ya se sentía como peruano:

Y yo estaba a popa... En proa estaban los españoles y en popa estaban los peruanos. Que ya me sentía peruanos como ellos. Si, me cayeron muy bien los peruanos ah... Bueno, conmigo eran muy buenos ah... Es que yo los respetaba. Hay gente que no respeta a nadie... Para mí todo el mundo es igual. Entonces me apreciaban: "Oe cholazo ${ }^{48}$, sabes para cualquier cosa estamos nosotros ah..." (Segundino Cuevas).

\footnotetext{
${ }^{47}$ Coishco es un distrito (pequeño Concello), puerto y zona industrial, ubicado a $473 \mathrm{~km}$. de Lima. Es capital de la provincia de Santa del departamento de Ancash y está muy cerca del puerto de Chimbote. En la actualidad sigue siendo sede de un importante conjunto de fábricas dedicadas a la industria pesquera.

${ }^{48}$ En este caso el término cholazo significa cholo grande, ello debido a la alta estatura de este malpicán. El término cholo encierra algunas veces un tono despectivo, aunque en el Perú también puede usarse como término de cariño y confianza. Cholo se refiere a aquel individuo indígena inmigrado hacia la ciudad y que ha atravesado o está en permanente proceso de aculturación.
} 
La referencia a la comida y bebidas peruanas también fueron siempre citadas por nuestros entrevistados, así como de la buena vida que llevaron en el Perú, pues a decir de un informante:

Se manejaba dinero... Había anchoa. La gente vivía bien, la fiesta, los cines que habia en Chimbote... Restaurantes, parrilladas de toda clase... De todo. Panaderías italianas, había de todo... (Entrevistado de 75 años. Trabajó como patrón de pesca en Chimbote).

Lima era una ciudad que muchos malpicáns frecuentaban en sus días libres, sea para pasear y en otros casos para regularizar su documentación de residencia. Un entrevistado nuestro debido a su afición al fútbol, solía viajar continuamente a la capital los fines de semana. Algunos gallegos que acumularon mucho capital adquirieron propiedades en Lima, incluso en su Centro Histórico y hacen referencia de amigos y familiares que aún viven en Lima y en el puerto del Callao.

La prosperidad y reputación que alcanzaron algunos gallegos en su inmigración al Perú, gracias a su esfuerzo y trabajo, eran nombradas en nuestras entrevistas: allí fui un rajá, un rajá de la India, señaló de ellos. Otro incluso nos dijo que sentía como un dios:
(...) Ya no venía más aquí, estaba muy bien allí. Ya estaba muy bien considerado, mucho por ahí. Yo por donde pasaba era el dios. Me querían (...) Yo también les quería mucho a esos, porque la ver- dad eran muy buenos conmigo eh. La gente era noble, inteligente porque aprendian enseguida. (...) Aprendian, tenían intención de aprender. Eran trabajadores (...) Daba gusto trabajar con ellos (Humberto Verdes).

Una mujer peruana que vive en Malpica desde hace más de 40 años y que se casó con un malpicán en Chimbote, nos habló de lo bien adaptados que estaban los gallegos en aquel puerto, pues incluso tenían hijos que habían nacido allí y que estudiaban en las escuelas del lugar. La prosperidad económica que alcanzaron muchos malpicáns, también fue mencionada por ella:

Porque fue una época de mucha anchoa. Todo el mundo vivía bien y el clima de allá era excepcional, era un buen ambiente. La gente se acostumbró muy bien allá y estaban todos muy contentos y así dice la gente: Si no fuera por el terremoto que desapareció la anchoa 
(Mujer peruana de 70 años. Casada con un malpicán que migró a Chimbote).

Sin embargo, también es importante mencionar que la migración hacia Chimbote, en un inicio con la llegada de los exiliados malpicáns, y luego por la búsqueda de trabajo, también produjo la separación de familias y los duelos consiguientes ${ }^{49}$ :

Rompió muchas familias. Había gente que estaba casada aquí, gente que tenía acá su trabajo... Esa fue una de las cosas más duras que produjo la migración hacia Perú, en tiempos de la guerra, no después. Después ya la gente se iba voluntariamente. Tenían familiares allá, les llamaban, iban a trabajar y a ganarse la vida... Mi abuela nunca más vio a mi abuelo, nunca más. Yo a mi abuelo nunca lo conocí... Mi madre tampoco estuvo con su padre y a mi tío recién lo conozco hace unos 5 ó 6 años, que se marchó un poquito antes de nacer yo y no volvió hasta ahora (...) Y esa es una de las cosas más duras y más tristes que produjo la emigración hacia América.

La parte positiva la rescata en que la gente que se marchó fue bien recibida en el Perú. Pudieron trabajar, pudieron subsistir. Pudieron incluso alguno mandarle... Un poquito como hacéis vosotros ahora aquí. Quiero decir: Oye desde allá con su trabajo y su esfuerzo, pues ayudar a la gente que estaba aquí. Incluso después reclamar gente de aquí, para que pudiera ir allá para trabajar... (Varón de 50 años aprox. Funcionario del Concello de Malpica de Bergantiños).

En esta parte, creemos que es necesario hace una cita textual de las palabras de un marinero malpicán que migró a Chimbote, el cual resume los ciclos históricos a los que de una u otra manera están sometidas las migraciones internacionales, a la migración anterior y a la actual, y a una pretendida reciprocidad que hay que cumplir con los inmigrados peruanos que hoy viven y trabajan en Malpica:

Yo pienso bien por qué... Porque yo... migré. Un día estando alli, allí donde se juntan los marineros todos... No eran peruanos,

\footnotetext{
${ }^{49}$ Para un mejor entendimiento de los procesos psicológicos o emocionales en los procesos de migración, Joseba AtxoteguI LoIZATE, "Los duelos de la migración: una aproximación psicopatológica y psicosocial", en Enrique Perdigueiro Gil y Josep M. Comelles (coords.), Medicina y Cultura. Estudios entre la antropología y la medicina, Barcelona, edicions Bellattera, 2008, págs. 83-100.
} 
eran chineses, indonesios... Eran grandazos, negros. Estaba uno que está en Coruña, que es malpicán, que se llama Francisco. Entonces Francisco andaba para buscarles sitio, tal, no les gustó; se fueron para Coruña. Entonces vienen los que dijeron: "Veee... negros de m..., id por allí, id para vuestra tierra, joder..." Eso lo dijeron ellos. Entonces entré a hablar y yo estaba, digo (dije) yo: "¿Vosotros estáis bien de la cabeza?”. Ellos: "Siempre defiendes a los extranjeros". Defiendo a los extranjeros porque yo me fui de casa y a mi me trataron bien. La vida es así, unos se van y otros se vienen. Vuestros padres ya fueron a Uruguay, ya fueron a Argentina, ya fueron a Cuba y ahora vienen para acá. Y a muchos peruanos que hay acá en Malpica y les digo yo: "Antes nosotros para Perú, ahora vosotros para España"... La vida da vueltas. Yo sé que es muy duro emigrar y por tanto más, sin hijos y sin mujer. Si estas solo no interesa, ijoder! ¿Es la verdad o no es la verdad? (Segundino Cuevas).

\section{EL RETORNO}

Habíamos mencionado anteriormente y en forma muy breve, algunas causas que motivaron que la gran mayoría de migrantes gallegos decidieran dejar Chimbote. Más allá de las cuestiones políticas de nacionalización de la industria pesquera o del terremoto que ocurrió en 1970, y evitando ser categóricos, creemos que también hay otros factores de suma importancia que trataremos de abordar.

A fines de los años cincuenta e inicios de los años sesenta el Perú se encontraba inmerso en una crisis política. El 17 de julio de 1962 los militares llevaron a cabo un golpe de Estado y retiraron al presidente Manuel Prado y el 18 de julio tomó el gobierno una Junta Militar que gobernaría el país hasta 1963, año en el que por elecciones generales fue elegido presidente nuevamente un civil. En ese contexto de desgobierno, el Estado peruano no tuvo la capacidad ni el interés de generar una política pesquera sostenible, lo que repercutió a su debacle en los años posteriores.

En 1955 en el Perú se producían entre unas 15.000 y 16.000 t. de harina de pescado, con un costo de producción de US\$ 55 por tonelada. Este increíble bajo costo atrajo el interés de muchos inversionistas que contribuyeron al continuo crecimiento de la industria. En 1956, un año después la producción ya se había duplicado (32.000 t.), tendencia que persistió en la década siguiente.

Debido a la alta demanda de la harina de pescado a nivel mundial y a la ausencia de una política coherente en el sector se produjo una caótica instalación de fábricas 
y un aumento importante de la flota de barcos pesqueros ${ }^{50}$. El mar empezó a ser depredado y se sobreexplotaron los bancos de peces. No se tomaron en cuenta los muchos factores que afectan la estabilidad de las poblaciones de anchoa, como las cuotas de pescas necesarias para dejar suficientes peces en el mar o las vedas pesqueras para asegurar una buena reproducción, así como un tamaño mínimo para proteger a los peces juveniles (Ver gráfico $\mathrm{N}^{\mathrm{o}} 2$ ). Las consecuencias se sintieron poco después y la crisis se manifestó con despidos masivos, la quiebra de muchas empresas, el incremento desproporcional de los costos de producción y una evidente sobrecapacidad de flota y de plantas procesadoras incapaces de auto sostenerse. Además el mar se llenó de desechos de pescado y Chimbote llegó a ser una ciudad sumamente contaminada, con un aire casi irrespirable ${ }^{51}$.

La tarde del 31 de mayo de 1970 fue un día de inflexión de la emigración gallega en este puerto del Pacífico. Aquel día Perú sufrió uno de los terremotos más devastadores de su historia, que afectó la costa y sierra del centro y norte del país. La zona más afectada fue precisamente el departamento de Ancash, donde está el puerto de Chimbote, donde murieron cerca de 3,000 personas, no encontrándose entre ellos a ningún gallego ${ }^{52}$. Estos al igual que los peruanos, tuvieron numerosas pérdidas materiales y sufrieron la destrucción de sus casas. Este fue el principal motivo para que, aproximadamente 200 familias gallegas decidieran regresar. Para ello contaron con el apoyo del Instituto Nacional de Emigración Española, que les ofreció la posibilidad de pagarle la mitad del precio del pasaje y ayudarles a obtener una vivienda y empleo una vez retornados ${ }^{53}$. Parte de estos hechos fueron relatados por Pedro Chouciño:

La gente de Malpica que vivía en Chimbote. El grueso, al grueso de las personas de Chimbote le afectó más el terremoto, porque aquello fue una desbandada, algo nunca visto, corrieron todos para Lima en menos de 24 horas. Felizmente para ellos se fueron. Pero la otra crisis, la peor, la crisis del general Velasco, la asumimos un grupo más reducido de españoles, los que quedamos aquí, los

\footnotetext{
${ }^{50}$ La harina de pescado es utilizada como alimento para aves, cerdos, rumiantes, vacas lecheras, ganado vacuno, ovino y el desarrollo de la piscicultura, disminuyendo con ello notablemente los costos de producción industrial de estos animales por su rápido crecimiento, su mejor nutrición, la mejora de la fertilidad y la notoria disminución de posibilidades de enfermedades.

${ }^{51}$ Ana Chouciño Fernandéz, "Sobre las olas: hacia Chimbote ida y vuelta...", pág. 944.

${ }^{52}$ Los departamentos más afectados por este sismo fueron Lima, Ancash, Huánuco y la Libertad. Las víctimas mortales sumaron 80.000 personas y los desaparecidos 20.000. Los heridos sumaron cerca de 150.000 personas y se calculó el número de afectados en 3.000.000.

${ }_{53}$ María Teresa García Domínguez, "Aproximación ó estudio da emigración galega cara a Perú...”, pág. 192.
} 
que todavía estamos aquí, esos fuimos los que sufrimos la crisis, unos más, otros menos, pero todos la sufrimos en carne propia ${ }^{54}$.

Un malpicán que fue testigo personal de este sismo, reafirma la anterior idea. Señaló que si no fuera por el terremoto, no hubiera regresado a Malpica, porque allá llevaba una vida maravillosa. Relató que:

Estábamos a punto de comprarnos una casa antes del terremoto, para quedarnos a vivir alli. Había gente que tenía edificios, que tenían que vender nomás al precio que querían (los compradores) para venir (Varón de 75 años. Trabajó como patrón de pesca en Chimbote).

Como lo narró el Sr. Chouciño, después del terremoto de 1970, sobrevinieron una serie de acontecimientos que afectaron a la pequeña comunidad gallega que aún quedaba en Chimbote, fruto de políticas estatistas que un nuevo gobierno militar había empezado a aplicar desde el año anterior. El 3 de octubre de 1968 había ocurrido otro golpe de Estado en el gobierno del Perú y también en esa ocasión, una Junta Militar Revolucionaria encabezada por el Gral. Juan Velasco Alvarado había asumido la dirección del país. Se aplicaron una serie de medidas de corte nacionalista y socialista, implementando un programa de nacionalizaciones de las empresas privadas de todos los sectores productivos, entre ellas las del sector pesquero. También se nacionalizaron los bancos y los medios de comunicación y se llevó a cabo una radical reforma agraria, que reemplazó la gran propiedad rural por la propiedad individual y comunitaria de los campesinos.

El gobierno militar creó el Ministerio de Pesquería a finales de 1969 y en mayo de 1970 se creó la Empresa Pública de Comercialización de Harina y Aceite de Pescado. En abril de 1971 se promulgó una nueva Ley de Pesquería que estableció el control del Estado sobre la comercialización de las exportaciones pesqueras, dispuso la eliminación progresiva del capital extranjero en el sector y sentó las bases para la participación de los trabajadores. En mayo de 1973 se creó la empresa Pesca Perú que dirigió el monopolio del Estado peruano en la industria de la harina y del aceite de pescado, la misma que absorbió a casi todas las empresas privadas ${ }^{55}$.

\footnotetext{
54 Televisión de Galicia, "A Aventura de Malpica no Perú”, Galicia no Mundo, [documento audiovisual], [s.1.], Televisión de Galicia, 1989.

${ }^{55}$ El gobierno militar tuvo como algunas excusas principales para implementar estas políticas de estatización en el sector pesquero: que la actividad pesquera se dedicaba casi exclusivamente a la producción de harina de pescado descuidando la pesca para consumo humano, en perjuicio de la
} 
Gráfico 2. Captura de anchoveta en toneladas métricas, para el período 1950-2006.

Fuente: Instituto del Mar del Perú IMARPE

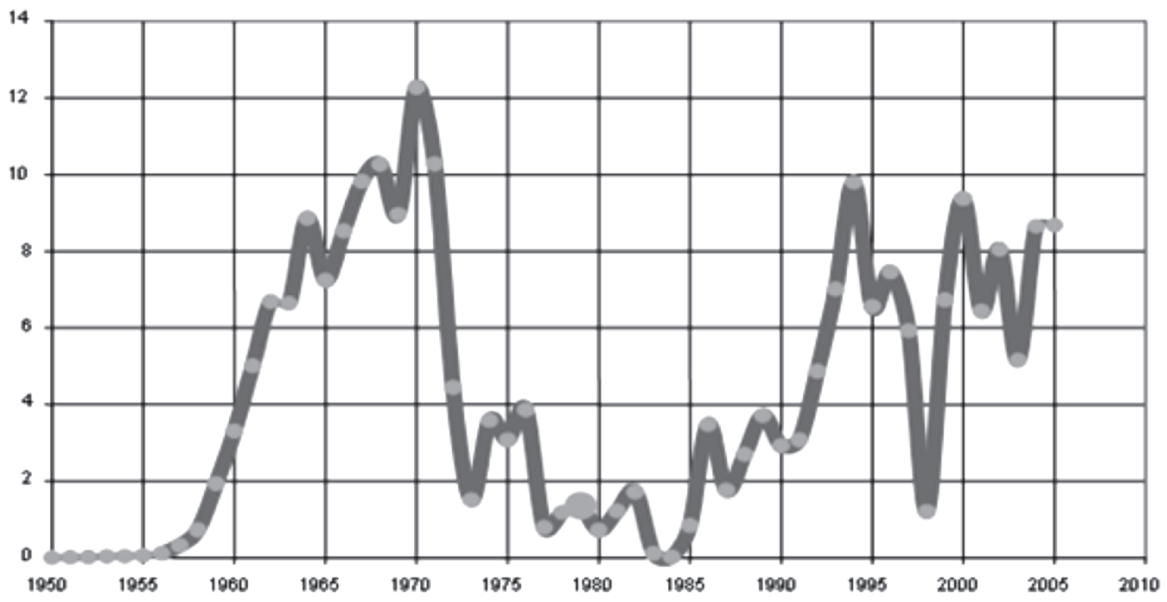

A lo anterior, sumamos que entre 1972 y 1973 ocurrió el fenómeno del Niño en el mar peruano, lo que ocasionó una disminución significativa de los bancos de peces $^{56}$. Estas difíciles circunstancias para el empresariado pesquero, condujeron a que los pocos gallegos que aún quedaban en Chimbote vendieran sus barcos y retornasen a España, aunque algunos se fueron a Lima y otros a Ecuador a seguir trabajando en la industria pesquera ${ }^{57}$. En 1977 ya no quedaba casi ningún malpicán en Chimbote.

Sin embargo, otros inmigrados malpicáns ya habían retornado antes del terremoto, por diferentes motivos. Para algunos las ganancias económicas no compensaban el estar lejos de su familia, otros retornaron por motivos de salud,

alimentación de la población; la existencia de grupos de poder económico nacionales y extranjeros que controlaban todas las etapas de la actividad pesquera y de la industrialización; y que estas empresas tenían serias deficiencias estructurales por el exceso de capacidad instalada.

${ }^{56}$ El Niño es un fenómeno climático erráticamente cíclico, que consiste en un cambio en los patrones de movimiento de las corrientes marinas en la zona intertropical, causando una superposición de aguas cálidas procedentes de la zona del hemisferio norte (costas del Ecuador y Colombia) sobre las aguas frías que caracterizan a la corriente de Humboldt (frente a las costas peruanas y chilenas). Esta situación produce una serie de estragos a escala zonal (en la zona intertropical), debido a las intensas lluvias, afectando principalmente a América del Sur y a sus costas en el lado del Pacífico, como del Atlántico. Debido a este "calentamiento" el ecosistema de las aguas frías del mar peruano se altera totalmente y los bancos de peces desaparecen y con ello toda una serie de aves y mamíferos que habitan en sus costas.

${ }^{57}$ Tal fue el caso de Celestino Garrido Pose y de otros gallegos que trabajaron con él, quienes se establecieron en Guayaquil. 
personales o de sus familiares y otros porque los cambios en la industria pesquera demandaban mayores riesgos:

\begin{abstract}
El primer barco que yo hice era de 35 pies, 6, 7, $8 \mathrm{~m}$. Pero para dentro de tres meses tenías que hacer un barco de $40 \mathrm{~m}$. Tenías que ir como ellos... Por eso la base de venir para aquí, fue porque yo ya me quedaba chico. Con los barcos que tenía ya me quedaba pequeño. Yo tenía unos barcos de 140 t., pero ellos estaban haciendo de 400 t., que son los que hay ahora, de 400 t. Yo tenía que otra vez invertir todo lo que había ganado en mi vida, invertirlo para hacer un barco de esos... Tengo que llevar algo también para vivir ¿no? (Humberto Verdes).
\end{abstract}

Muchos de los proyectos migratorios de los gallegos en el Perú fueron satisfactorios a nivel económico y otros, por supuesto que no lo fueron. Sin embargo en sus recuerdos afloran los amigos, la vida cotidiana, sus trabajos, la comida, los lugares, las anécdotas y experiencias que constituyen una huella mucho más profunda que se entremezcla con imágenes de su esfuerzo, trabajo, proyectos, miedos, fracasos y éxitos, que son sinónimo para muchos de ellos, del Perú.

\title{
CONCLUSIÓN
}

La migración de los malpicáns al Perú y específicamente hacia Chimbote entre 1950-1970 tiene características muy particulares, pues fue motivada por un enclave económico muy específico. Aunque también se enmarca dentro de una migración de tipo laboral y familiar, fue la intensa actividad pesquera en este país y la coincidencia de la presencia de un primer grupo de malpicáns (exiliados políticos), la que impulsó esta migración y que encontró en este nicho laboral, su punto de concentración y luego de disolución.

En la migración desde Malpica de Bergantiños hacia Chimbote, al igual que en las pasadas y actuales migraciones internacionales se destaca la importancia de las cadenas y redes migratorias para el impulso o retracción de un flujo migratorio. Para este caso particular, un exilio político en Chile propició otra migración en búsqueda de empleo y de subsistencia en el Perú, que devino con los años en la constitución de una clase empresarial y otra trabajadora, ambas gallegas, que supieron aprovechar los abundantes recursos del mar peruano, la flexibilidad de una política de recepción de emigrantes extranjeros, así como la facilidad para la implementación de empresas con capital y mano de obra extranjera. Estos dos últimos, siguen siendo parte de la política migratoria para la llegada de extranjeros al Perú. 


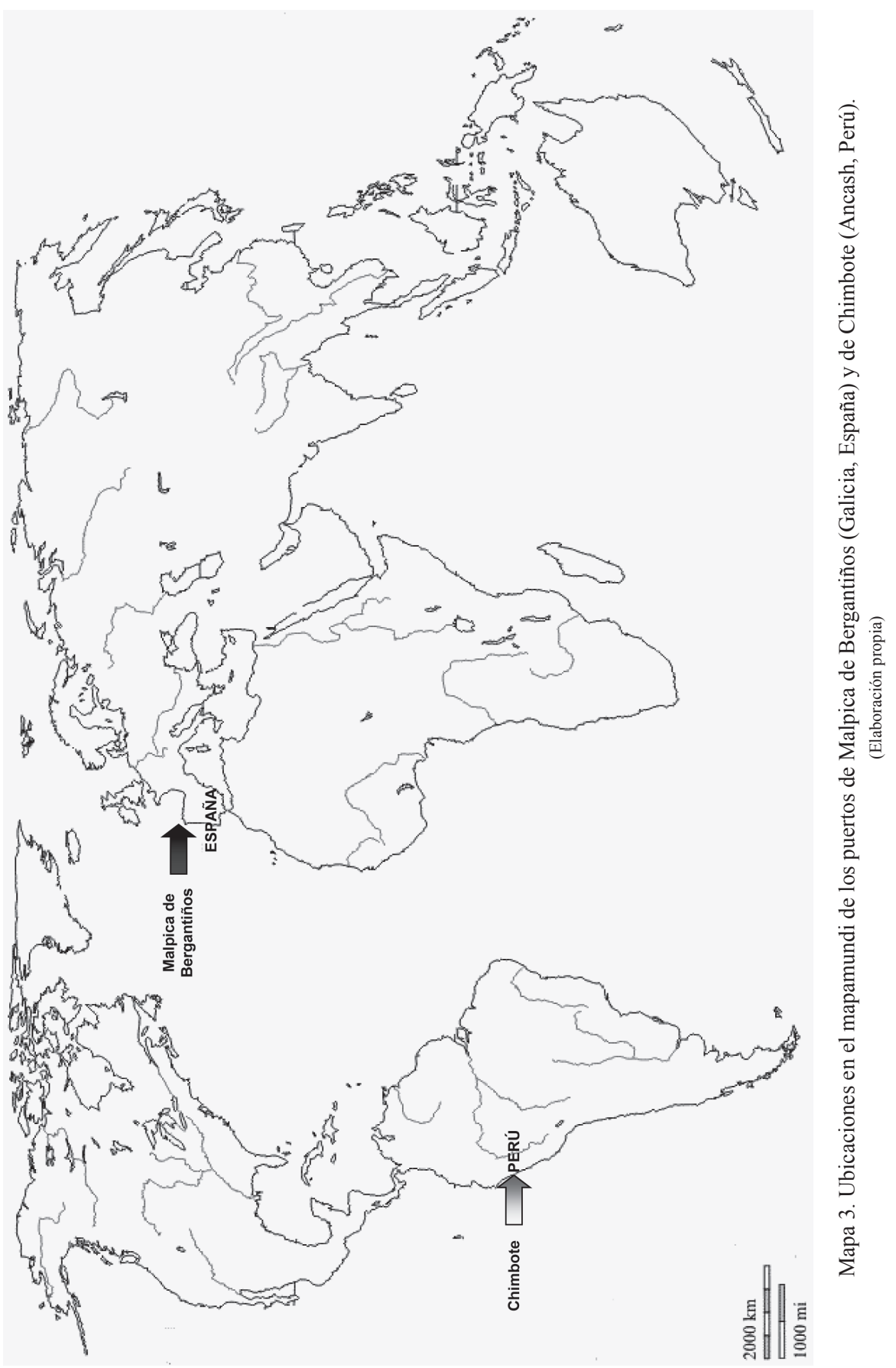


Los primeros malpicáns en Chimbote, en su calidad de exiliados políticos (republicanos, anarquistas y comunistas), tuvieron que haber atravesado un proceso de acomodo personal, para empezar a formar una naciente clase empresarial. Éstos son un grupo diferenciado respecto a los malpicáns que llegarían posteriormente a este puerto peruano, con lo que se hace evidente un cambio generacional en este flujo migratorio. La migración posterior de las familias y amigos de los primeros, fue en un tiempo y en un contexto diferente, tanto por las motivaciones, como por los objetivos que persiguieron.

El derecho a migrar de todas las personas y a buscar un mejor empleo y bienestar para sus familias se desprende en este trabajo. Los relatos obtenidos sobre la migración malpicán hacia Chimbote de parte de sus propios protagonistas, aunque no indiquen proyectos migratorios insatisfechos, nos sirven para rescatar las experiencias de quienes vivieron en carne propia la migración y de todas las dificultades que esta puede conllevar. Así, podemos reconocer que las migraciones internacionales son en muchos casos, flujos de ida y de vuelta desde los mismos puntos de partida y llegada en diferentes momentos históricos. Prueba de ello, es la actual emigración de jóvenes españoles hacia Latinoamérica, una vez más.

\section{BIBLIOGRAFÍA}

Atxotegui Loizate, Joseba, "Los duelos de la migración: una aproximación psicopatológica y psicosocial", en Enrique Perdigueiro Gil y Josep M. Comelles (coords.), Medicina y Cultura. Estudios entre la antropología y la medicina, Barcelona, Edicions Bellattera, 2008, págs. 83-100.

Candeira Carballido, Marta, Los hermanos Barcia: caucheros y filántropos, Vigo, Editorial Galicia en el Mundo, 2010 (Colección Crónicas de la Emigración).

Chouciño Fernández, Ana, "Sobre las olas: hacia Chimbote ida y vuelta", en XIV Encuentro de Latinoamericanistas Españoles: congreso internacional, Santiago de Compostela, Universidade de Santiago de Compostela, 2010, págs. 938-948.

Diana Mandiá, Santiago, "El ayer de Malpica pasa por Perú", El País [en línea], disponible en <www.elpaís.com/diario/2010/01/07/galicia/1262863099_850215.html> [Consulta: 16/04/2012].

Eiras Roel, Antonio y Rey Castelao, Ofelia, Los gallegos y América, Madrid, Editorial MAPFRE, 1992.

Fernández Sendín, Maximino, Alfonso I de la Amazonía Rey de los Jibaros, Pontevedra, Autor-editor, 2005.

García Domínguez, María Teresa, “A Emigración Galega a América no Século XX: O caso peruano", en Roberto Irimia-Vásquez y Juan Francisco Froján Fontán (coordinadores), I Encontros Galicia- América, Santiago de Compostela, CIHUGA, 1992, págs. $27-29$.

García Domínguez, María Teresa, “Aproximación ó estudio da emigración galega da "Costa da Morte” cara a Perú na segunda metade do século XX (1940-1970)", Estudios Migratorios, 5 (1998), págs.177-198. 
García Domínguez, María Teresa,"A emigración galega cara a América durante a segunda mitade do século XX", en Pilar Cagiao Vila (compiladora), Galegos en América e Americanos en Galicia: as colectividades inmigrantes en América e a súa impronta na sociedade galega, séculos XIX-XX, Santiago de Compostela, Xunta de Galicia, 1999, págs. 73-75.

García Domínguez, María Teresa, “Outros países de acollida: Chile, Perú”, en Pilar Cagiao Vila (coordinadora), A emigración galega a América do Sur, A Coruña, Hércules de Ediciones, 2013, págs. 304-357.

Granovetter, Mark, Getting a Job: A Study of Contacts and Careers, Chicago, University of Chicago Press, 1995.

Grieco, Margaret, Keeping it in the family: social networks and employment chance, London and New York, Tavistock Publications, 1987.

La Parra Casado, Daniel, "Violencia estructural y migración: Las instituciones sociales en España”, en Francisco Hidalgo (editor), Migraciones. Un juego con cartas marcadas, Quito, Ediciones Abya-Yala, 2004, págs. 233-255.

La Voz de Galicia, [en línea], disponible en <www.lavozdegalicia.es/carballo/ 2009/12/15/0003_8172553.htm> [Consulta: 06/05/2012].

Martínez Riaza, Ascensión, A pesar del Gobierno: Españoles en el Perú, 1879-1939, Madrid, Consejo Superior de Investigaciones Científicas, 2006 (Colección América, 4).

Pedone, Claudia, Tu siempre jalas a los tuyos. Cadenas y redes migratorias de las familias ecuatorianas hacia España, Barcelona, Universitat Autònoma de Barcelona, Facultad de Filosofia i Lletres, Departament de Geografía, 2003.

Pedone, Claudia, "Cadenas y redes migratorias: propuesta metodológica para el análisis diacrónico-temporal de los procesos migratorios", Empiria. Revista de Metodología de Ciencias Sociales, 19 (2010), págs. 101-132.

Romero, Santiago, "La Gran Odisea", La Opinión A Coruña [en línea], disponible en <www. laopinioncoruna.es/estaticos/domingo/20070902/domingo.html> [Consulta: 06/05/2012].

Sala i Vila, Nuria, "Cobertura y desamparo: garantías jurídicas de los españoles en el Perú (1870-1945)", Anuario de Estudios Americanos, 66,1 (enero-junio.2009), págs. 103-113.

Sabbatiello, Mónica, "La lenta agonía de los indianos de Malpica (I). El cólera casi arruina a las industrias gallegas en Perú", El Correo Gallego (25 de marzo de 1991), págs. 12-13.

Sayad, Abdelmalek, La Doble Ausencia. De las ilusiones del emigrado a los padecimientos del inmigrado, Barcelona, Anthropos Editorial, 2010.

Televisión de Galicia, “A Aventura de Malpica no Perú”, Galicia no Mundo, [documento audiovisual], [s.1.], Televisión de Galicia, 1989.

Vázquez González, Alexandre, “A emigración galega contemporánea”, en Xosé Cid Fernández, Xoán Dominguez Alberte y Raúl Sotelo Vásquez (coords.) Migracións na Galicia contemporánea. Desafios para a sociedade actual, Santiago de Compostela, Sotelo Blanco edicións, 2008, págs. 18-36. 
